Original Article

\title{
The effects of cervical traction, cranial rhythmic impulse, and Mckenzie exercise on headache and cervical muscle stiffness in episodic tension-type headache patients
}

\author{
Sung-Yong Chol, PT, MS ${ }^{1)}$, Jung-Hyun Chol, PT, $\mathrm{PhD}^{1)^{*}}$ \\ 1) Department of Physical Therapy, Namseoul University: 21 Maeju-ri, Sungwan-eup, Seobuk-Gu, \\ Chonan-Si 331-707, Republic of Korea
}

\begin{abstract}
Purpose] The purpose of this study was to examine the effects of cervical traction treatment, cranial rhythmic impulse treatment, a manual therapy, and McKenzie exercise, a dynamic strengthening exercise, on patients who have the neck muscle stiffness of the infrequent episodic tension-type (IETTH) headache and frequent episodic tension-type headache(FETTH), as well as to provide the basic materials for clinical interventions. [Subjects] Twenty-seven subjects (males: 15, females: 12) who were diagnosed with IETTH and FETTH after treatment by a neurologist were divided into three groups: (a cervical traction group (CTG, $n=9$ ), a cranial rhythmic contractiongroup (CRIG, $n=9$ ), and a McKenzie exercise group (MEG, $n=9$ ). An intervention was conducted for each group and the differences in their degrees of neck pain and changes in muscle tone were observed. [Results] In the within-group comparison of each group, headache significantly decreased in CTG. According to the results of the analysis of the muscle tone of the upper trapezius, there was a statistically significant difference in MEG on the right side and in CRIG on the left side. According to the results of the analysis of the muscle tone of the sternocleidomastoid muscle, there was a statistically significant difference in MEG on the right side and in CRIG on the left side. [Conclusion] In the comparison of the splenius capitis muscle between the groups, there was a statistically significant difference on the right side. Hence, compared to the other methods, cervical traction is concluded to be more effective at reducing headaches in IETTH and FETTH patients.

Key words: Cervical traction, Cranial rhythmic impulse, McKenzie exercise
\end{abstract}

(This article was submitted Oct. 21, 2015, and was accepted Dec. 2, 2015)

\section{INTRODUCTION}

Recently, thanks to the popularization of computers and changes in work environments that include an increased use of computers, work-related musculoskeletal disorders (WRMSDs) have surged among computer users ${ }^{1)}$.

WRMSDs cause continuous damage to parts of the body, such as the muscles, joints, and nerves, due to continuous repetitive work, such as computer use, and result in occupational lesions, through the accumulation of continuous damage. The symptoms occur in the upper limb articular area, the head, the neck, and the shoulders, and as a result, there has been a rapid increase in the number of patients who visit hospitals ${ }^{2}$. In addition, the use of small mobile visual display cellular phones affects users' neck and shoulder muscles more than existing imaging terminals, such as desktop computers ${ }^{3)}$. Small mobile visual display terminals damage neck and shoulder muscles and trigger headaches. Headache is a very common disease that is experienced by about $96.7 \%$ of the total population during their lifetime, and the prevalence of tension-type headache, one of the most common types of headache for a year, is $86 \%^{4}$. Headache is a very common clinical symptom,

*Corresponding author. Jung-Hyun Choi (E-mail: rightmind@nsu.ac.kr)

(C2016 The Society of Physical Therapy Science. Published by IPEC Inc.

This is an open-access article distributed under the terms of the Creative Commons Attribution Non-Commercial No Derivatives (by-nc-nd) License $<$ http://creativecommons.org/licenses/by-nc-nd/4.0/>. 
and it has been reported that in local communities, 65 to $80 \%$ of women and 57 to $75 \%$ of men experience headache ${ }^{5}$. The types of headache are divided differently according to the era, standards, and symptoms. According to the classification by the International Headache Society, the frequency of tension-type headache is next to that of migraine ${ }^{6}$. Here, tension refers to tension in the head and neck and mental tension ${ }^{7}$. All pain in the head is called headache, but its aspects are divided into a few types. Tension-type headache has been expressed differently based on its symptoms: muscle contraction headache, tension headache, pyschogenic headache, psychomyogenic headache, stress headache, essential headache, and nonmigrainous headache ${ }^{8}$. While the major mechanism in infrequent episodic tension-type headache (IETTH) and frequent episodic tension-type headache (FETTH) is considered to be a peripheral pain mechanism, a central pain mechanism is regarded as more important in chronic tension-type headache $\left.(\mathrm{CTTH})^{9},{ }^{10}\right)$. FETTH is classified into idiopathic and chronic types. It has been reported that idiopathic tension-type headache refers to headache that occurs at least once per month and 10 times per year, and has a pain frequency of less than 15 days a month, and that chronic tension-type headache has a frequency of at least 15 days a month or more than 180 days per year ${ }^{9)}$. In research on fascial pain trigger points, the distribution of referred pain by the trigger points of the head, neck, and shoulder areas has been reported to be almost the same as that of the areas where pain occurs in tension-type headache patients, and clinical characteristics of postural abnormality such as forward head posture and decreases in the cervical spinal range of motion have also been reported ${ }^{11-15)}$.

Physical therapies for headache patients include manipulation, joint range of motion, massage, cold packs, home exercise programs, advice on posture, muscle stretching techniques, retraining, razor, and acupuncture, and such treatment methods are said to stabilize a patient's psychological condition ${ }^{16-18)}$.

Hoving et al. noted that active treatment, in which tension-type headache patients participated, was helpful for symptom management and may improve physical symptoms ${ }^{19)}$. However, Jordan et al. observed that in the treatment and management of cervical pain, the effects of active treatment (such as therapeutic exercise) appeared largely for a short time period, and this was similar to the effects of the passive pain alleviation treatment methods ${ }^{20}$. In addition, Vilijanen et al. noted that dynamic muscular training and relaxation training were not effective for the cervical pain of headache patients ${ }^{21)}$. Regarding the association between headache and the cervical spine, Antonaci and Bogduk illuminated the anatomical basis and mechanism of cervical spine triggering headache, but this has a mechanism of cervical pain, and research on the association between tension-type headache and the cervical spine is lacking ${ }^{22,23)}$. In addition, domestic research on morphological changes in the cervical spine in tension-type headache patients is insufficient, and the scientific grounds for treatment effects have not been sufficiently demonstrated. Nevertheless, based on the advantages of treatments and the appropriateness of many theories, diverse exercise treatments such as mobility exercise, extension exercise, isometric exercise, and dynamic strengthening exercise are being performed according to clinical therapists' decisions ${ }^{24}$. Accordingly, this study examined the effects of cranial rhythmic impulse (CRI) treatment, McKenzie exercise, a dynamic strengthening exercise, and mechanical cervical traction treatment, a manual therapy on headache and cervical area muscle stiffness of IETTH and FETTH patients, thereby intending to provide evidence for these therapeutic approaches and their effects for clinical therapists.

\section{SUBJECTS AND METHODS}

In research by Gracia the average age of tension-type headache patients was 47.4 years old. Therefore, this study recruited subjects with ages between 40 and 49 years old ${ }^{25}$. The participants were 27 patients (males: 15, females: 12) who visited C hospital located in Seongnam City, complained of headache and tenderness in the cervical muscle, and were diagnosed with IETTH or FETTH after treatment by a neurologist. The criteria for exclusion were CTTH patients, patients with headache resulting from traumatic injuries, patients with headache caused by a terminal stage disease (such as meningitis or brain cancer), and pregnant women. All participants were instructed about the potential risks and experimental design and provided their informed consent to participation, with the knowledge that they could withdraw at any time. The Ethics Committee of Namseoul University in Korea also approved this study. The IRB approval number is Research-NSU-1041479-201510HR-003.

The subjects comprised three groups: the cervical traction group (CRG), the cranial rhythmic impulse group (CRIG), and the McKenzie exercise group (MEG). For the first group, the posterior area of the cervical spine was extended using cervical traction. At present, the generally used treatment is sustained traction ${ }^{26)}$, because continuous traction triggers pain in the patients; therefore, it is difficult to maintain sufficient traction force for a long time. Hence, it was decided to apply sustained traction. For the purpose of extending the posterior area of the cervical spine, while maintaining a comfortable posture, the patients lay in a supine position, flexed the neck at 20 to 30 degrees, and pulled a rope horizontally at 60 degrees. The traction force was generated with 8 to $14 \mathrm{~kg}$ of weight and the pulling was conducted for a total of 20 minutes using sustained traction, with a traction time of 10 seconds and a resting time of 10 seconds ${ }^{27)}$. The second group received CRI treatment. This treatment separats cervical vertebra 1 and the occipital bone and relaxs the stiffness of the larynx bone ${ }^{28)}$. The fingers of both hands (excluding the thumbs) were put together vertically and held up high and the fingers were held erect like the blade of a knife in the forward direction. Treatment was applied for three minutes followed by with a one minute break, for a total of five times, for a total of 20 minutes. The third group performed exercise by themselves using repetitive exercise as a treatment strategy of McKenzie, mobilization exercise, manipulation, and patient education. The Mackenzie exercises performed in this experiment consisted of seven motions: four motions of extension, two motions of lateral flexion and rotation, and one 
Table 1. General characteristics of the subjects

\begin{tabular}{lccc}
\hline & $\begin{array}{c}\text { CTG } \\
(\mathrm{M} \pm \mathrm{SD})\end{array}$ & $\begin{array}{c}\text { CRIG } \\
(\mathrm{M} \pm \mathrm{SD})\end{array}$ & $\begin{array}{c}\text { MEG } \\
(\mathrm{M} \pm \mathrm{SD})\end{array}$ \\
\hline Age (years) & $44.5 \pm 3.4$ & $43.8 \pm 2.1$ & $41.7 \pm 1.5$ \\
Gender $(\mathrm{M} / \mathrm{F})$ & $5 / 4$ & $5 / 4$ & $5 / 4$ \\
Height $(\mathrm{cm})$ & $164.2 \pm 10.7$ & $166.2 \pm 7.7$ & $165.3 \pm 7.1$ \\
Weight $(\mathrm{kg})$ & $63.7 \pm 8.9$ & $63.3 \pm 10.7$ & $66.8 \pm 12.6$ \\
\hline Values are Mean \pm SD. $\mathrm{p}<0.05$ & & \\
CTG: cervical traction group, CRIG: cranial rhythmic impulse group, MEG: McKenzie exercise \\
group
\end{tabular}

motion of flexion ${ }^{29}$.

This experiment employed a visual analogue scale (VAS) in order to evalute the degree of tenderness in the subjects' neck muscles and the degree of headache before and after the treatment. On a $10 \mathrm{~cm}$ line without markings, the subjects marked the degree of headache and tenderness of their neck muscles. Then the distance from the start point to the subjects' marks was measured and scored. This scale is a pain measurement scale with high reproducibility in the evaluation of subjects' expression of their degree of pain. It is the most widely used method for evaluating the intensity of pain, and it has a reported reliability of ranging from $\mathrm{r}=0.76$ to $0.84^{30}$ ).

Myoton PRO (Myoton AS, Estonia), a muscle tone measurer, was used in this experiment to measure the degree of stiffness of the neck muscles. Eight areas were measured: the anterior temporal muscle, sternocleidomastoid muscle, upper trapezius muscle, and the splenius capitis muscle on both the left and right sides. Before and after the five-day treatment, the left and right sides of the muscles were measured. The muscle belly areas of the anterior temporal muscle, sternocleidomastoid muscle, and upper trapezius muscle were measured three times in a supine position, and the average values were used as the measured values. The muscle belly areas of the left and right sides of the splenius capitis muscle were measured three times in a prone position, and the average values were used as the measured values. The interval between the measurement time points was 10 seconds. The skin was pushed with $0.18 \mathrm{~N}$ of force and after this pre-load, a force of $0.58 \mathrm{~N}$ was momentarily applied to the skin at intervals of $15 \mathrm{~ms}$. Thereafter, the vibration on the skin surface was triggered by Myoton PRO (Myoton AS, Estonia), a muscle tone measurer, which was used to examine the biomechanic indices. The reported Inter-rater reliability ranges from $\mathrm{r}=0.97$ to 0.99 , and that of the intra-rater reliability ranges from $\mathrm{r}=0.98$ to $0.99^{31)}$. In previous research, normal subjects' muscle characteristics changed after stretching ${ }^{32)}$, and company workers who used computers for a long time showed differences in muscle characteristics between before and after noon ${ }^{33)}$.

To analyze the data in this study, the statistics program, SPSS 18.0, was used. The general characteristics of the subjects of this study have been expressed using frequency analysis, means, and standard deviations (Table 1). To compare the differences between the groups in headache and stiffness changes, one-way analysis of variance was carried out and the Tukey test was conducted as a post-hoc test. In addition, to examine the differences in headache and stiffness within each group before and after each intervention, the paired t-test was conducted. For verification of a statistical significance, the significance level of $\alpha=0.05$ was chosen.

\section{RESULTS}

The comparison of the intervention effects within each of the three groups showed that headache significantly decreased in CTG $(p<0.05)$. There were no statistically significant changes in each of the three groups in tenderness $(p>0.05)$, and there was no statistically significant change in headache in CRIG or MEG ( $>0.05)$. Among the three groups, there were no statistically significant change in either tenderness or headache $(p>0.05)$ (Table 2$)$.

According to the results of the analysis of the changes in the muscle tone of the upper trapezius, only the right side of MEG and the left side of CRIG significantly differed $(p<0.05)$. According to the results of the analysis of the changes in the muscle tone of the sternocleidomastoid muscle, the right side of MEG and the left side of CRIG significantly differed within each group $(p<0.05)$. According to the results of the analysis of the changes in the muscle tone of the splenius capitis muscle, there was a statistically significant difference only on the left side of CTG $(p<0.05)$. In the comparison of the splenius capitis among the groups, a statistically significant difference was found onthe right side $(p<0.05)$. According to the results of the analysis of the changes in the muscle tone of the anterior temporal muscle, there was a statistically significant difference only in the right side of CTG $(\mathrm{p}<0.05)$ (Table 3$)$.

\section{DISCUSSION}

The types of headache are divided differently according to the era, standards, and symptoms. According to the classification by the International Headache Society, the frequency of tension-type headache is next to that of migraine ${ }^{6}$. Headache 
Table 2. McKenzie self-exercise method and order

\begin{tabular}{|c|c|c|}
\hline Order & Method & $\begin{array}{l}\text { Application time and } \\
\text { number of times }\end{array}$ \\
\hline $\begin{array}{l}\text { Pulling behind the } \\
\text { head in a sitting } \\
\text { posture }\end{array}$ & $\begin{array}{l}\text { The subject sits on a chair comfortably, straightens his or her back, and looks } \\
\text { straight ahead. Then the subject puts the second and third right fingers on the lower } \\
\text { chin and pulls it posterior inferiorly. }\end{array}$ & \multirow{7}{*}{$\begin{array}{l}\text { The subject conducts } \\
\text { each motion by him } \\
\text { or herself and sus- } \\
\text { tains the motion at the } \\
\text { static maximal muscle } \\
\text { strength for seven } \\
\text { seconds, repeats the } \\
\text { d motion } 15 \text { times, and } \\
\text { conducts the motion for } \\
\text { a total of } 20 \text { minutes. }\end{array}$} \\
\hline $\begin{array}{l}\text { Bending the head } \\
\text { backward in } \\
\text { a sitting posture }\end{array}$ & $\begin{array}{l}\text { The subject sits on a chair comfortably, straightens his or her back, and looks } \\
\text { straight ahead. While bending the head backward, the subject rotates the head in } \\
\text { the right and left directions. }\end{array}$ & \\
\hline $\begin{array}{l}\text { Pulling the chin } \\
\text { inward in a supine } \\
\text { position }\end{array}$ & $\begin{array}{l}\text { In a supine position on a bed, the subject pulls his or her head toward the bottom of } \\
\text { the bed and at the same time pulls the lower chin toward his or her chest. }\end{array}$ & \\
\hline $\begin{array}{l}\text { Bending the } \\
\text { head backward in a } \\
\text { supine position }\end{array}$ & $\begin{array}{l}\text { In a supine position, the subject lies on a bed with the shoulder line at the final line } \\
\text { of the edge of the bed and bends the head back toward the bottom. While bending } \\
\text { the head back, the subject rotates the head in the right and left directions. }\end{array}$ & \\
\hline $\begin{array}{l}\text { Bending the neck to } \\
\text { the side }\end{array}$ & $\begin{array}{l}\text { The subject sits on a chair comfortably, straightens his or her back, and looks } \\
\text { straight ahead. Bending the head toward the right shoulder direction as maximally } \\
\text { as possible, the subject holds the temporal region of the left side of the head with } \\
\text { the right hand and pulls it in the direction of the right shoulder. If the subject needs } \\
\text { to conduct the exercise of bending the head toward the opposite direction, the } \\
\text { subject holds the temporal region of the right side of the head with the left hand and } \\
\text { pulls it in the direction of the left shoulder. }\end{array}$ & \\
\hline Head rotation & $\begin{array}{l}\text { The subject sits on a chair comfortably, straightens his or her back, and looks } \\
\text { straight ahead. With the head rotated to the right, the subject holds the left lower } \\
\text { chin with the right palm and holds the temporal region of the right side of the head } \\
\text { with the left palm and then pulls the head further to the right. If the subject needs } \\
\text { to conduct the exercise of rotating the head in the opposite direction, the subject } \\
\text { holds the right lower chin with the left palm and the temporal region of the left side } \\
\text { of the head with the right palm and then rotates the head further to the left. }\end{array}$ & \\
\hline $\begin{array}{l}\text { Inclining the head } \\
\text { in a sitting posture }\end{array}$ & $\begin{array}{l}\text { The subject sits on a chair comfortably, straightens his or her back, and looks } \\
\text { straight ahead. While locking his or her fingers together on the back of the neck, } \\
\text { the subject inclines the head forward and then pulls the head further with both } \\
\text { hands. }\end{array}$ & \\
\hline
\end{tabular}

Table 3. Comparison of VAS headache scores

\begin{tabular}{llcc}
\hline Item & Group & $\begin{array}{c}\text { Pre } \\
(\mathrm{M} \pm \mathrm{SD})\end{array}$ & $\begin{array}{c}\text { Post } \\
(\mathrm{M} \pm \mathrm{SD})\end{array}$ \\
\hline \multirow{3}{*}{ Headache } & $\mathrm{CTG}^{*}$ & $4.00 \pm 1.2$ & $3.17 \pm 1.1$ \\
& CRIG & $6.00 \pm 1.2$ & $4.33 \pm 2.0$ \\
& MEG & $4.17 \pm 0.7$ & $3.83 \pm 0.9$ \\
\hline
\end{tabular}

Values are mean \pm SE. ${ }^{*} \mathrm{p}<0.05$. Significant difference between the pre- and post-tests within each group. CTG: cervical traction group; CRIG: cranial rhythmic impulse group; MEG: McKenzie exercise group

triggers damage to the neck and shoulder muscles. Headache is a common disease that about $96.7 \%$ of the total population experiences. The prevalence of the most common type of headache, the tension-type headache, for a year is about $86 \%{ }^{4)}$. Among the total of 27 subjects, the number of males was 15 and the number of females was 12 . They were divided into three groups: CTG, CRIG, and MEG. In a test of the homogeneity of the subjects' general characteristics—age, gender, height, and weight — no statistically significant differences were found ( $>0.05)$. Headache is a very common clinical symptom, and it has been reported that in a local community 65 to $80 \%$ of women and 57 to $75 \%$ of men had experienced headache ${ }^{5)}$. The cause of the higher incidence in women was because women have relatively lower neck muscles and are therefore exposed to muscle fatigue more easily. Additionally, weakening of the cervical spine extensor, cervical spine flexor, cervical spine extensor and flexor, and cervical rotator leads to the easy occurrence of cervical pain ${ }^{32-37)}$. However, according to the results of the changes in the VAS scores of headache, in the comparison of the intervention effects within the three group, headache showed a significantly decrease in CTG $(p<0.05)$, but not in CRIG or MEG. In the comparison among the groups, there was 
Table 4. Comparison of the scores of stiffness of the neck muscles (unit: N/m)

\begin{tabular}{|c|c|c|c|c|}
\hline Muscle & Side & Group & $\begin{array}{c}\text { Pre } \\
(\mathrm{M} \pm \mathrm{SD})\end{array}$ & $\begin{array}{c}\text { Post } \\
(\mathrm{M} \pm \mathrm{SD})\end{array}$ \\
\hline \multirow{6}{*}{ Upper trapezius muscle } & \multirow{3}{*}{ Rt } & CTG & $217.3 \pm 12.1$ & $211.8 \pm 8.9$ \\
\hline & & CRIG & $252.3 \pm 37.8$ & $229.0 \pm 21.7$ \\
\hline & & $\mathrm{MEG}^{*}$ & $215.5 \pm 16.4$ & $209.5 \pm 16.2$ \\
\hline & \multirow{3}{*}{$\mathrm{Lt}$} & CTG & $207.6 \pm 11.9$ & $206.3 \pm 8.0$ \\
\hline & & CRIG $^{*}$ & $236.1 \pm 30.5$ & $222.8 \pm 20.8$ \\
\hline & & MEG & $205.5 \pm 22.1$ & $202.8 \pm 21.6$ \\
\hline \multirow{6}{*}{ Sternocleidomastoid muscle } & \multirow{3}{*}{ Rt } & CTG & $195.5 \pm 12.4$ & $190.3 \pm 13.0$ \\
\hline & & CRIG & $258.3 \pm 72.7$ & $255.1 \pm 55.6$ \\
\hline & & $\mathrm{MEG}^{*}$ & $199.3 \pm 17.0$ & $196.1 \pm 16.9$ \\
\hline & \multirow{3}{*}{$\mathrm{Lt}$} & CTG & $211.1 \pm 7.2$ & $202.3 \pm 10.3$ \\
\hline & & CRIG & $232.1 \pm 33.3$ & $233.1 \pm 29.9$ \\
\hline & & MEG & $208.0 \pm 11.9$ & $203.1 \pm 9.7$ \\
\hline \multirow{6}{*}{ Splenius capitis muscle } & \multirow{3}{*}{$\mathrm{Rt}^{1,2}$} & CTG & $311.0 \pm 32.3$ & $277.1 \pm 37.5$ \\
\hline & & CRIG & $293.6 \pm 80.8$ & $334.5 \pm 110.5$ \\
\hline & & MEG & $307.5 \pm 32.3$ & $307.3 \pm 28.7$ \\
\hline & \multirow{4}{*}{$\mathrm{Lt}$} & $\mathrm{CTG}^{*}$ & $325.3 \pm 30.3$ & $288.0 \pm 29.1$ \\
\hline & & CRIG & $298.1 \pm 73.3$ & $266.8 \pm 51.7$ \\
\hline & & MEG & $282.8 \pm 40.2$ & $284.0 \pm 38.9$ \\
\hline \multirow{6}{*}{ Anterior temporal muscle } & & CTG $^{*}$ & $740.5 \pm 15.9$ & $729.5 \pm 11.8$ \\
\hline & \multirow[t]{3}{*}{ Rt } & CRIG & $740.5 \pm 23.5$ & $743.0 \pm 22.5$ \\
\hline & & MEG & $721.0 \pm 26.3$ & $707.1 \pm 42.4$ \\
\hline & & CTG & $728.6 \pm 35.7$ & $720.8 \pm 17.8$ \\
\hline & \multirow[t]{2}{*}{$\mathrm{Lt}$} & CRIG & $749.5 \pm 16.5$ & $742.1 \pm 18.8$ \\
\hline & & MEG & $730.3 \pm 20.0$ & $722.3 \pm 28.5$ \\
\hline
\end{tabular}

Values are mean \pm SE, ${ }^{*} p<0.05$ Significant difference between the pre- and post-tests within each group. Significant difference among the group; ${ }^{1} \mathrm{CTG}$ : cervical traction group; ${ }^{2} \mathrm{CRIG}$ : cranial rhythmic impulse group; ${ }^{3} \mathrm{MEG}$ : McKenzie exercise group

no significant change in headache. Therefore, in episodic tension-type headache patients, the treatment methods other than CTG did not contribute much to the alleviation of headache, and the treatment effects in CTG were also insufficient. This is consistent with the report by Vilijanen et al. that dynamic muscle training and relaxation training are not effective for tension-type headache patients' cervical pain ${ }^{21)}$. However, this result is not consistent the resultsthat of a study by Kim ${ }^{38)}$, who found that there were a differences in range of motion (ROM), VAS, and pressure pain thresholds in an active relaxation therapy group, but not in a range of motion exercise group. In previous research, as characteristics related to headache, the most frequently expressed symptom accompanying headache was pain in the neck and shoulders, and stress and fatigue were the factors that triggered headache most often ${ }^{39)}$. The pathological physiological mechanism of tension-type headache has not been firmly established, but muscle contraction and psychological factors are thought to act in a complex manner ${ }^{40)}$. In other previous research, a digital algometer, Commander ${ }^{\mathrm{TM}}$ was used to measure the pressure pain thresholds of the anterior temporal muscle, sternocleidomastoid muscle, splenius capitis muscle, and trapezius muscle with a method devised by Fracton et al. ${ }^{41)}$, and in the tension-type headache patient group, significant changes, in the masseter muscle, trapezius muscle, and temporal muscle ${ }^{42}$. The present study utilized a muscle tension measurer Myoton PRO instead of the Commander ${ }^{\mathrm{TM}}$ algometer and measured the changes in the left and right stiffness of the upper trapezius muscle, sternocleidomastoid muscle, anterior temporal muscle, and splenius capitis muscle after the treatments. According to the results of the analysis of the muscle tone changes of the upper trapezius, there were a statistically significants difference in the right side of MEG and the left side of CRIG. According to the results of the analysis of the muscle tone changes of the sternocleidomastoid muscle, there was a statistically significant difference on the right side of MEG and the left side of CRIG. According to the results of the analysis the muscle tone changes of the splenius capitis muscle, there was a statistically significant difference on the left side of CTG, and according to the comparison of the muscle tone changes of the splenius capitis muscle among the three groups, there was a statistically significant difference in the right side of CTG (Table 4). According to the results of the analysis the muscle tone changes of the anterior temporal muscle, there was a statistically significant difference on the right side of CTG. This result is consistent with a study by Cassidy et al. who observed that when joint range of motion exercise was performed by to 100 patients complaining of cervical pain, their range of motion in flexion, extension, lateral flexion, and 
rotation increased ${ }^{43)}$. In addition, Hall and Robinson noted that manual therapy of the upper cervical spine resolved stiffness in the occipital region, improved blood flow disturbances, and reduced the pain duration of tension-type headache patients ${ }^{44)}$.

In the present study, was treated with cervical traction, CRI, and McKenzie exercise, and low frequency and high frequency episodic tension-type headache patients some muscles showed significant changes. However, This study did not adequately demostrate which of the three methods had better therapeutic effects on which muscles. The number of subjects in each group was small and the study period was short; therefore, it was not possible to conclude whether contraction of the cervical muscles was the cause of headache, and it is difficult to generalize the results of this study. Future research on the correlation between headache and the stiffness of cervical muscles should be conducted.

\section{ACKNOWLEDGEMENT}

The funding for this study was provided by Namseoul University.

\section{REFERENCES}

1) Tepper M, Vollenbroek-Hutten MM, Hermens HJ, et al.: The effect of an ergonomic computer device on muscle activity of the upper trapezius muscle during typing. Appl Ergon, 2003, 34: 125-130. [Medline] [CrossRef]

2) Jeon HY: The effects of holy-relax of proprioceptive neuromuscular facilitation on craniocervical. Unpublished doctoral dissertation, Daegu University, 2006 (in Korea).

3) Szeto GP, Lee R: An ergonomic evaluation comparing desktop, notebook, and subnotebook computers. Arch Phys Med Rehabil, 2002, 83: 527-532. [Medline] [CrossRef]

4) Stovner LJ, Zwart JA, Hagen K, et al.: Epidemiology of headache in Europe. Eur J Neurol, 2006, 13: 333-345. [Medline] [CrossRef]

5) Choi HL: Treatments of ambulatory care patientwith headache. J Korean Acad Fam Med, 1999, 20: 555-565.

6) Headache Classification Committee of the International Headache Society: Classification and diagnostic criteria for headache disorders, cranial neuralgias and facial pain. Cephalalgia, 1988, 8: 1-96. [Medline]

7) Olesen J, Jensen R: Getting away from simple muscle contraction as a mechanism of tension-type headache. Pain, 1991, 46: 123-124. [Medline] [CrossRef]

8) Olesen J, Tfelt-Hansen P, Welch KM: The Headache. New York: Raven Press, 1993, pp 439-443.

9) Kim BK: What is the New of International Classification of Headache Disorders, 3rd ed. The Korean Headache Society, 2013, 14: 51-57.

10) Bendtsen L, Fernández-de-la-Peñas C: The role of muscles in tension-type headache. Curr Pain Headache Rep, 2011, 15: 451-458. [Medline] [CrossRef]

11) Fernández-de-Las-Peñas $C$, Ge HY, Arendt-Nielsen L, et al.: The local and referred pain from myofascial trigger points in the temporalis muscle contributes to pain profile in chronic tension-type headache. Clin J Pain, 2007, 23: 786-792. [Medline] [CrossRef]

12) Fernández-de-Las-Peñas C, Ge HY, Arendt-Nielsen L, et al.: Referred pain from trapezius muscle trigger points shares similar characteristics with chronic tension type headache. Eur J Pain, 2007, 11: 475-482. [Medline] [CrossRef]

13) Fernández-de-las-Peñas $\mathrm{C}$, Alonso-Blanco $\mathrm{C}$, Cuadrado ML, et al.: Trigger points in the suboccipital muscles and forward head posture in tension-type headache. Headache, 2006, 46: 454-460. [Medline] [CrossRef]

14) Lee JH, Park SJ, Na SS: The effect of proprioceptive neuromuscular facilitation therapy on pain and function. J Phys Ther Sci, 2013, 25: 713-716. [Medline] [CrossRef]

15) Bae Y: Change the myofascial pain and range of motion of the temporomandibular joint following kinesio taping of latent myofascial trigger points in the sternocleidomastoid muscle. J Phys Ther Sci, 2014, 26: 1321-1324. [Medline] [CrossRef]

16) Boline PD, Kassak K, Bronfort G, et al.: Spinal manipulation vs. amitriptyline for the treatment of chronic tension-type headaches: a randomized clinical trial. J Manipulative Physiol Ther, 1995, 18: 148-154. [Medline]

17) Hammill JM, Cook TM, Rosecrance JC: Effectiveness of a physical therapy regimen in the treatment of tension-type headache. Headache, 1996, 36: 149-153.

18) Kim SD: Effects of yoga exercises for headaches: a systematic review of randomized controlled trials. J Phys Ther Sci, 2015, 27: 2377-2380. [Medline] [CrossRef] 
19) Hoving JL, Koes BW, de Vet HC, et al.: Manual therapy, physical therapy, or continued care by a general practitioner for patients with neck pain. A randomized, controlled trial. Ann Intern Med, 2002, 136: 713-722. [Medline] [CrossRef]

20) Jordan A, Bendix T, Nielsen $H$, et al.: Intensive training, physiotherapy, or manipulation for patients with chronic neck pain. A prospective, single-blinded, randomized clinical trial. Spine, 1998, 23: 311-318, discussion 319. [Medline] [CrossRef]

21) Viljanen M, Malmivaara A, Uitti J: Effectiveness of dynamic muscle training. relaxation training or ordinary activity for chronic neck pain: randomized controlled trail. BMJ, 2003, 327: 1-5. [Medline] [CrossRef]

22) Antonaci F, Bono G, Chimento P: Diagnosing cervicogenic headache. J Headache Pain, 2006, 7: 145-148. [Medline] [CrossRef]

23) Bogduk N: The anatomical basis for cervicogenic headache. J Manipulative Physiol Ther, 1992, 15: 67-70. [Medline]

24) Sarig-Bahat H: Evidence for exercise therapy in mechanical neck disorders. Man Ther, 2003, 8: 10-20. [Medline] [CrossRef]

25) Gracia-Naya M Grupo de Estudio de Neurólogos Aragoneses: [Chronic tension headache in the neurological outpatient clinics]. Rev Neurol, 2000, 31: 929-932. [Medline]

26) Harris PR: Cervical traction. Review of literature and treatment guidelines. Phys Ther, 1977, 57: 910-914. [Medline]

27) Crue BL, Todd EM: The importance of flexion in cervical halter traction. Bull Los Angel Neuro Soc, 1965, 30: 95-98. [Medline]

28) Ventegodt S, Merrick J, Andersen NJ, et al.: A combination of gestalt therapy, Rosen Body Work, and Cranio Sacral therapy did not help in chronic whiplash-associated disorders (WAD) — results of a randomized clinical trial. ScientificWorldJournal, 2004, 4: 1055-1068. [Medline] [CrossRef]

29) Mckenzie RA: Treat your own neck. 3rd ed. Wellington: Spinal Publication, 1985.

30) Boonstra MC, De Waal Malefijt MC, Verdonschot N: How to quantify knee function after total knee arthroplasty? Knee, 2008, 15: 390-395. [Medline] [CrossRef]

31) Viir R, Laiho K, Kramarenko J, et al.: Repeatability of trapezius muscle tone assessment by a myometric methos. J Mech Med Biol, 2006, 6: 215-228. [CrossRef]

32) Myoton: General principles of applying myoton in high-performance sport. Myoton Medical Technology, 2008.

33) Kim SH, Jo SP, Park JH, et al.: Development of driver fatigue evaluation method by body pressure distribution measurment. Ergonomics Society of Korea, Spring Conference, 2013.

34) Jordan A, Mehlsen J: Cervicobrachial syndrome and neck muscle function; effects of rehabilitation. J Musculoskeletal Pain, 1993, 1: 283-288. [CrossRef]

35) Barnsley L, Lord SM, Bongduk N: The pathophysiology of whiplash. Spine State Art Rev, 1993, 7: 329.

36) Chiu TT, Sing KL: Evaluation of cervical range of motion and isometric neck muscle strength: reliability and validity. Clin Rehabil, 2002, 16: 851-858. [Medline] [CrossRef]

37) Ylinen J, Takala EP, Kautiainen H, et al.: Association of neck pain, disability and neck pain during maximal effort with neck muscle strength and range of movement in women with chronic non-specific neck pain. Eur J Pain, 2004, 8: 473-478. [Medline] [CrossRef]

38) Kim JH, Lee HS, Park SW: Effects of the active release technique on pain and range of motion of patients with chronic neck pain. J Phys Ther Sci, 2015, 27: 2461-2464. [Medline] [CrossRef]

39) Choi JS, Park HS: The Effects of Craniosacral Therapy on Chronic Headache. Kor Acad Soc Rehabil Nur, 2004, 7: 68-77.

40) Kim BM, No JG, Park SH: Diagnosis and Treatment of Headache. Hyundae Publication, 2000, pp 1-125.

41) Fricton JR, Bromaghim C, Kroening RJ: Physical Evaluation: The Need for a Standarized Examination. In: Fricton JR, Kroening RJ, Hathaway KM, eds. TMJ and Craniofasial Pain: Diagnosis and Management. St. Louis: Ishiyaku EuroAmerical Inc., 1988, 39.

42) Neumann DA: Kinesiology of the Musculoskeletal System: Foundations for Rehabilitation, 2nd ed. Mosby, 2009, 315341.

43) Cassidy JD, Lopes AA, Yong-Hing K: The immediate effect of manipulation versus mobilization on pain and range of motion in the cervical spine: a randomized controlled trial. J Manipulative Physiol Ther, 1992, 15: 570-575. [Medline]

44) Hall T, Robinson K: The flexion-rotation test and active cervical mobility-a comparative measurement study in cervicogenic headache. Man Ther, 2004, 9: 197-202. [Medline] [CrossRef] 